Work in Progress: Collaborative Learning in Medical Electronics Laboratory

Mr. Jorge E Bohorquez, University of Miami

Dr. Jorge Bohórquez received his bachelor degrees in Physics and Electrical engineering in 1984 and his Ph.D. degree in Biomedical Engineering in 1991. Currently Dr. Bohórquez works as an assistant professor of Professional Practice at the Department of Biomedical Engineering of the University of Miami. His research interests are Engineering Education, Neural Engineering, Biosignal Processing and Instrumentation.

Dr. Jonathon Anthony Toft-Nielsen 


\title{
Work in Progress: Collaborative Learning in Medical Electronics Laboratory
}

\begin{abstract}
Background: Modern industry requires engineers to function as effective team members, exhibiting strong communication and problem solving skills [1]. Collaborative learning improves not only the academic achievement of students, but also their interpersonal skills. ABET requires engineering programs to incorporate collaboration in their curriculum and assess the student's collaborative skills. Despite all this evidence, engineering education typically remains more inclined towards individualistic or competitive learning.

Design/Method: An existing laboratory course was overhauled and refocused to boost student's skills in design, crafting, self-efficacy, troubleshooting, and expertise in the field of Medical Electronics. The strategy was to use problem oriented methodology in a collaborative setup. Results: The main learning objectives were fulfilled and students reported a high level of satisfaction with the content and the methodology of the course.
\end{abstract}

\section{Introduction}

Collaboration in education is seen as joining intellectual efforts between groups of students or between students and instructors to achieve a common goal. Collaborative learning is the heart of problem-based learning, which emphasizes a more "natural learning" [2]. Cooperative learning represents an active field of research in education and there is a consensus about its positive effects on the academic achievement of students at all schooling levels [3]. The meta-analysis performed by Johnson et al., on the impact of cooperative learning on college students [2], shows substantial, significant improvement of student achievement in cooperative settings compared with competitive or individualistic learning settings. In addition, the studies showed improvement in students' relationships and psychological health. In engineering education, two recent studies showed that, under the appropriate conditions, the students in cooperative learning performed better that the ones in individualistic learning conditions $[4,5]$. The importance of collaborative learning is further reinforced by the ABET accreditation process, which requires accredited programs to assess the collaborative skills of students in engineering programs.

Despite the evidence of the benefits and the necessity of teaching collaboration skills to engineering students, engineering educators usually underutilize the power of academic teams. There is a broad consensus that effective cooperative learning is difficult to implement, requiring a number of key elements to be in place in order to become a powerful tool $[3,4,5,6]$. Our experience shows that simply assigning students to groups and asking them to work together doesn't guarantee an effective collaborative effort. Stump et al. [5] presents the barriers to collaborative learning as they apply to engineering education; they include 1) the instructional practice that promotes high competition and focuses students' goals on course grades and 2) the use of problems with only a single answer. The competitive environment reduces the wiliness of students to collaborate as it pressures them to outperform their classmates and to avoid situations that can give a "bad impression" to the instructor and/or the classmates. As a consequence, the students become reluctant to ask for help and to provide help to others. The use of closed problems with a single correct answer doesn't give room for collaboration.

In the present work in progress we present a problem-oriented medical electronics laboratory, designed to significantly enhance the expertise, self-efficacy, and design and craftsmanship skills of biomedical engineering (BME) students by using collaborative learning. This work is part of our long term goal to find teaching methods to efficiently teach a broad 
spectrum of electronic concepts with a limited course credit impact, in order to enable BMEs to become effective users of electronics technology in the medical field [7,8].

\section{Implementation of collaborative learning in the medical electronics laboratory}

The general learning objective of the medical electronics laboratory (MEDELAB) is to present and consolidate all of the principles of the design of microcomputer based medical instruments; this main objective encompasses the following specific ones: 1) to use systematic methods for the development of devices: specifications, analysis, simulation, implementation and testing; 2) to have in consideration safety, noise and power consumption; 3) to use CAD tools for schematic capture, simulation and PCB routing; 4) to understand the basic configurations and specifications of medical power supplies and 5) to write microcontroller DSP software for real time acquisition, storage and transmission of biomedical data.

MEDELAB is the most advanced required course for BME students following electrical concentration. The course serves as a sort of capstone, consolidating the various skills students have acquired over their studies in the context of real world design problems. The class met weekly for $4 \frac{1}{3}$ hours; the first hour was dedicated to a conventional, procedural microprocessor laboratory, while last $3 \frac{1}{3}$ hours were dedicated to MEDELAB, working in teams of four students working in realistic, open ended design problems.

\section{Team dynamic and behavior rules}

The class was divided in two teams of four students. In each team, the instructor assigned individual responsibilities in each of the following aspects: 1) Microcontroller hardware and software, 2) Signal processing and display software; 3) Analog circuits and 4) power supplies. The task definition and individual responsibility assignment required the necessity of collaborative interactions between students as many tasks involved various topics. For example in the specifications and architectural design tasks, all the students worked together to define how signals would flow between modules; students gathered together again during the testing tasks. The following rules were established to facilitate and reward the collaboration and learning:

a) Personal accountability vs. team performance: Each student was responsible as individual for his product assignment (for example microcontroller HW\&SW) while the team was responsible for the product.

b) Co-tutoring: During the evaluation of the project any student could be required to explain, in detail, any design/implementation aspect. Students trained each other about their own specific aspect.

c) Any type of intra-team collaboration was allowed and encouraged.

d) Switching assignments: Each student was not allowed to have the same type of assignment in two different projects. With this rule every student had hands-on experience with all the design aspects.

\section{Project 1: Design and test of an Optical Pulse Meter}

Description: Teams implemented, from scratch, a pulse meter using as input a medical finger SPO2 sensor containing two light sources (Red and IR) and a photodiode. The system worked in dual architecture having microcontroller based data acquisition module connected to a Lab View module for DSP and display.

Project statement: A detailed top- down project design methodology, including nine tasks, was defined. The tasks included: specification; architectural design; module testing design; hardware 
design; software design and complete implementation and testing. Students were required to formally document the achievement of each task in deliverables and in a formal final report.

\section{Project 2: Design and build and test an OEM based medical oxygen saturation device}

Description: The students used an OEM SPO2 module to build a fully functional, autonomous Oxygen Saturation Device. The instructor provided each team with a different OEM module (KTMED OEM module KSM-02 and Nonin ${ }^{\mathrm{TM}}$ iPod module) that performed the basic SPO2 measurement and transmitted the results using a proprietary serial protocol. The students were required to implement the communication protocol in their microcontrollers and build and test the remaining modules: user IO interface, power supply and software.

Project statement: The instructor presented a loosely-defined top- down project design methodology that included only three primary tasks. The first assignment given to the teams was to write a detailed development proposal to develop the project in a very tight time schedule; individual student responsibilities (roles) were also defined by the team. The instructor provided feedback/approval for the designs before the implementation.

\section{Project 3: Design and testing an ECG based, fully autonomous, heart rate monitor}

Description: In this project each team fully developed an electro-tachometer device. That integrates all the educational objectives of the course: analog electronics, microcontrollers, realtime DSP, user interface, etc. Each team was treated as a small company and the instructors played the role of the customers. The project objective was defined in one sentence and a set of functional specifications of the device were provided.

\section{Results}

The individual and team performance in the development and documentation of the projects indicate the instructors that the learning objectives were satisfied: the students learned and consolidated a considerable amount of knowledge and their design and craftsmanship skills were significantly improved. A student survey was performed to assess the student's experiences with the adopted teaching modality; their inputs to their perceived strengths and weaknesses of the approach and their achievement level. The table I, below, presents the quantitative survey's results:

Table I. Student perception of the importance (I) and achievement level (A) of the Learning and Educational Objectives (1: low importancelattainment, 2: neutral, 3 fair and $4 \mathrm{good}$ ) the survey was responded by seven of the eight students

\begin{tabular}{|c|l|l|}
\hline Learning Objective & I & A \\
\hline $\begin{array}{l}\text { 1. Use systematic design and testing } \\
\text { methods. }\end{array}$ & $\mathbf{4 . 7}$ & $\mathbf{4 . 3}$ \\
\hline $\begin{array}{l}\text { 2. To have in consideration safety, } \\
\text { noise and power consumption }\end{array}$ & $\mathbf{3 . 6}$ & $\mathbf{3 . 0}$ \\
\hline $\begin{array}{l}\text { 3. To use CAD tools for schematic } \\
\text { capture, simulation and PCB routing }\end{array}$ & $\mathbf{4 . 1}$ & $\mathbf{3 . 1}$ \\
\hline $\begin{array}{l}\text { 4. To have a basic understanding of } \\
\text { medical power supplies }\end{array}$ & $\mathbf{3 . 9}$ & $\mathbf{3 . 9}$ \\
\hline $\begin{array}{l}\text { 5. To write microcontroller software } \\
\text { for real time acquisition, storage and } \\
\text { transmission of biomedical data }\end{array}$ & $\mathbf{4 . 0}$ & $\mathbf{4 . 3}$ \\
\hline
\end{tabular}

\begin{tabular}{|c|l|l|}
\hline \multicolumn{1}{|c|}{ Educational Objective } & I & A \\
\hline $\begin{array}{l}\text { 1. Consolidate the knowledge and skills of } \\
\text { engineering principles }\end{array}$ & 4.3 & $\mathbf{4 . 1}$ \\
\hline $\begin{array}{l}\text { 2. The projects, the course rules and schedule } \\
\text { helped to effective team-work skills }\end{array}$ & $\mathbf{4 . 1}$ & $\mathbf{3 . 9}$ \\
\hline $\begin{array}{l}\text { 3. Students assumed different roles: analog, } \\
\text { microcontroller, power supply and DSP }\end{array}$ & $\mathbf{4 . 3}$ & $\mathbf{4 . 6}$ \\
\hline $\begin{array}{l}\text { 4. Collaboration: students teach each other } \\
\text { specific about design/implementation aspects }\end{array}$ & $\mathbf{4 . 1}$ & $\mathbf{4 . 3}$ \\
\hline $\begin{array}{l}\text { 5. Each student perceives himself as a part of a } \\
\text { team and feels that his/her personal success is } \\
\text { linked the success of the team }\end{array}$ & $\mathbf{4 . 6}$ & $\mathbf{4 . 0}$ \\
\hline $\begin{array}{l}\text { 6. Each student perceives to have clearly defined } \\
\text { individual accountability }\end{array}$ & $\mathbf{4 . 4}$ & $\mathbf{4 . 0}$ \\
\hline
\end{tabular}


In general the students gave high importance to the learning objectives; the highest $(4.7 / 5)$ is the objective 1 while the lowest (3.6/5) is the objective 2 . Regarding achievement level the highest were objectives 1 and $5(4.3 / 5)$ while the lowest were objectives 2 and 3 , getting only a fair achievement level (3/5). Students gave high importance and good achievement level to all educational objectives. Regarding the open feedback, the students acknowledge the problem oriented methodology as very positive and engaging with comments like "There is immense satisfaction in creating something that works, which allows one to look back at the whole design process fondly, despite any difficulties." and "I think learning by solving problems increase selfmotivation and improves the creativity". Regarding collaborative learning the comments were highly positive and include comments as: "I saw that collaborative learning speed up the learning time."; "working as a team helped better understand the programs and helped with the time schedule." and "Working collaboratively allowed me get used to taking on greater responsibility: a collaborator knows that if he/she fails, the whole team fails."

\section{Discussion}

This work in progress provided, so far, encouraging preliminary results in the achievement of the learning and educational objectives. Improvements can be done in the achievement of learning objectives 2 and 3. One student suggested in the survey using a blended methodology with the introduction of few lectures that can deal with topics, like patient safety, difficult to approach in a problem based only approach. The presentation of realistic problems creates an environment that allows the integration of many disparate concepts and gives students a deeper understanding of engineering principles. The authors verified firsthand many of the proposed key elements [2] that overcome the difficulties associated with cooperative learning. Strategies like: 1) allowing each student to perceive themselves as a part of a team and to feel that his/her personal success is linked the success of the team; 2) to have clearly defined individual accountability; 3) to create an environment that promotes and support student collaboration 4) having long weekly sessions to give the students enough time to engage each other and the project at hand.

\section{References}

1. National Academy of Engineering (NAE). (2004). The engineer of 2020: Visions of engineering in the new century. Washington, D.C: The National Academies Press.

2. Johnson, David W., Roger T. Johnson, and Karl A. Smith. Cooperative Learning Returns to College What Evidence Is There That It Works? Change: The Magazine of Higher Learning 30.4 (1998): 26-35.

3. R. Slavin, E. Hurley and A. Chamberlain. Cooperative Learning and Achievement: Theory and Research. In W. Reynolds and G. Miller Volume Editors, I. Weiner Editor in-chief; Handbook of Psychology, Volume 7 Educational Psychology, pp177-198. John Wiley \& Sons 2003.

4. CM Hsiung. The Effectiveness of Cooperative Learning, Journal of Engineering Education January 2012 , Vol. 101, No. 1, pp. 119-137

5. G. Stump, J. Hilperta, J. Husman, W. Chung and W. Kim. Collaborative Learning in Engineering Students: Gender and Achievement. Journal of Engineering Education July 2011, Vol. 100, No. 3, pp. 475-497

6. Guzdial, Mark, et al. The challenge of collaborative learning in engineering and math. Frontiers in Education Conference, 2001. 31st Annual. Vol. 1. IEEE, 2001.

7. Jorge E Bohórquez, Ozcan Ozdamar, Jonathon Toft-Nielsen, "Teaching Medical electronics to Biomedical Engineering Students: A Problem Oriented Approach", Proceedings of the 2011 ASEE Annual Conference \& Exposition, Vancouver, BC, Canada, June 2011

8. Jonathon Toft-Nielsen, Jorge E Bohórquez, Qian Shen, "Teaching Virtual Instrumentation to Biomedical Engineering Students", Proceedings of the 2012 Annual Conference of the Southeastern Section of the American Society of Engineering Education ASEE, StarkVille, Mississippi, USA, April 2012 